\title{
INTRODUCGIÓN: EL PERIODO PRESIDENCIAL DE FELIPE CALDERÓN HINOJOSA
}

\author{
Reynaldo Yunuen Ortega Ortiz \\ Ma. Fernanda Somuano Ventura
}

El SEXenio de Felipe Calderón representó la segunda presidencia panista en la historia de México; por desgracia para este país, muy probablemente este periodo será recordado como el más violento de los últimos cincuenta años. Felipe Calderón llega a la presidencia a partir de una elección seriamente cuestionada por uno de los contendientes y por una parte importante de la población, lo que de alguna manera condicionó la trama y el final. El proceso electoral de 2006, por mucho el más competido en la historia reciente del país, sacó a la luz varios de los problemas que tendrían que enfrentar los partidos y las instituciones electorales en los siguientes años. La diferencia entre Felipe Calderón y Andrés Manuel López Obrador fue de $.56 \%$. El candidato de la Coalición por el Bien de Todos no aceptó los resultados electorales, pues consideró que se había cometido un fraude, conque inició un movimiento de resistencia civil.

Aunado a lo anterior, Calderón asume la presidencia en un escenario de seguridad muy complicado: tiene que hacer frente al control territorial de zonas del país por parte del narcotráfico; una guerra entre cárteles de la droga; conflictos con Estados Unidos por la narcoviolencia en la frontera; un flujo constante de drogas hacia el país del norte y un aumento considerable del consumo de drogas ilícitas en México. En ese contexto decide combatir frontalmente al narcotráfico y reformar las instituciones del Estado en materia de seguridad. Los resultados distaron mucho de ser exitosos, la violencia escaló a niveles altísimos, el número de víctimas 
derivadas de aquélla también creció de manera exorbitante y los carteles no se replegaron ni disminuyeron su ritmo de actividad.

En materia económica se pueden señalar como elementos positivos que, durante el sexenio calderonista, se vivió la inflación más baja de la historia, una acumulación récord de reservas internacionales y una deuda pública estable. No obstante y según el informe de la Cuenta Pública 2012, elaborado por la Auditoría Superior de la Federación, el promedio del PIB en dicho sexenio fue de $1.9 \%$, lejos del 3.2 pronosticado. Ese "limitado crecimiento se reflejó en precarias oportunidades de empleo formal" y agravó la informalidad, "lo que implicó bajos ingresos, reducida productividad y carencia de seguridad social y servicios de salud". Así, de las personas ocupadas, $73.1 \%$ (35.9 millones) percibió ingresos de entre uno y cinco salarios mínimos generales; y la población desocupada pasó de 1.6 a 2.5 millones de 2007 a 2012.

El número de Foro Internacional que el lector sostiene propone como objetivo reunir distintos trabajos que desde diversas perspectivas hacen una evaluación detallada y profunda del sexenio de Felipe Calderón como presidente de México. Así, en el primer artículo Lorenzo Meyer hace una dura crítica al gobierno presidido por Calderón al argumentar que su gobierno fue notoriamente ineficaz e insensible en sus respuestas al incremento de la violencia, "que la guerra contra el narco no dio el resultado que esperaban los que la decidieron", y que "la acción nunca fue bien pensada ni diseñada, pues predominó el uso de la fuerza por sobre el trabajo de inteligencia”. Meyer señala también que durante este periodo hubo una tendencia desfavorable para los trabajadores, como demuestra la baja de los salarios y la mano dura discrecional contra algunos sindicatos, como fue el caso del Sindicato Mexicano de Electricistas.

El autor señala que diversos hechos en el calderonismo estuvieron determinados por los actores privados que asumieron funciones estatales y que se propusieron usar recursos políticos y económicos para mantener sus privilegios y aumentar su extracción de rentas. Estos grupos eran los grandes sindicatos corporativos, caciques regionales, empresas monopólicas y el crimen organizado. Meyer afirma que el calderonismo no pudo dar forma 
a un proyecto político atractivo para el público ni recuperar la confianza institucional de los ciudadanos. Concluye que a partir de 2006 la democracia no sólo no se profundizó, sino que incluso hubo una regresión, y que el regreso del PRI al poder "se debió menos al respaldo vigoroso de la ciudadanía y más al fracaso del panismo”.

Este último argumento es el que desarrolla Rogelio Hernández en su contribución a este número. Hernández explica de manera clara el destino del PRI durante los doce años de panismo. De acuerdo con el autor, el PRI sobrevivió a cambios políticos, reformas electorales y dos derrotas en las contiendas presidenciales gracias a la construcción de un liderazgo, a su historia, a las oportunidades que los gobiernos de la alternancia le brindaron y a sus fuentes tradicionales de apoyo: la política local y estatal.

Hernández muestra cómo el PRI fue capaz de resistir la alternancia, competir, ganar y renovar a sus élites, sobre todo estatales. En un contexto en el que carecía del liderazgo presidencial que antes de la alternancia lo mantenía unido como partido nacional, al convertirse en árbitro y autoridad final, el partido dispersó su poder en liderazgos institucionales (gubernaturas y bancadas legislativas) y en grupos diversos. Como era tradicional en el PRI, los liderazgos más fuertes fueron los locales, encabezados por quienes conservaron el poder después de 2000 y quienes se hicieron cargo de las maquinarias electorales estatales. El autor concluye destacando la renovación de la élite priista y su coexistencia con los priistas tradicionales en el gabinete del presidente Peña Nieto.

La alternancia política en el año 2000 abrió amplias expectativas en todos los ámbitos; el de la administración pública no fue la excepción. Ya desde la administración de Vicente Fox, la agenda de modernización administrativa fue muy ambiciosa y apostó por la Nueva Gerencia Pública y la transformación de la relación del gobierno con los ciudadanos. El artículo de María del Carmen Pardo analiza el proyecto de modernización administrativa del gobierno de Felipe Calderón. La autora afirma que la complejidad del contexto político y económico no permitió que dicho proyecto fuera prioritario en la agenda gubernamental. Tanto la crisis de legitimidad derivada de los resultados electorales de 2006, como la crisis financiera mundial de 2008 causaron que la política de austeridad 
administrativa opacara la posibilidad de que la modernización administrativa se convirtiera en prioridad del gobierno calderonista.

De acuerdo con la autora, las medidas más destacadas en el ámbito de la Administración Pública en ese periodo fueron la implementación del Sistema de Evaluación del Desempeño y la Matriz de Indicadores para Resultados, pero señala que fueron más medidas aisladas con un enfoque gerencial, que parte de un proyecto de largo aliento. Si bien los procesos de cambio tuvieron como enfoque central el presupuesto, esto dio lugar a prácticas que tomaron por sorpresa a los funcionarios, sobre todo porque aún no existe una cultura de la evaluación consolidada en la administración pública en México.

En resumen, estos tres primeros artículos muestran las dificultades que desde un inicio enfrentó el gobierno de Felipe Calderón: la crisis de legitimidad derivada de la elección presidencial, la crisis económica mundial de 2008 y el aumento de los niveles de violencia asociados al narcotráfico. Los tres hacen su análisis con un enfoque que podría enmarcarse dentro del institucionalismo histórico, pues todos ellos sitúan a distintas instituciones como artífices u obstáculos del cambio político. Los artículos de Meyer y Pardo muestran la dificultad del cambio institucional más allá de la formalidad, ya sea por la inercia de ciertas trayectorias institucionales que persisten en el tiempo, ya por cambios en el contexto político y económico que constriñen las posibilidades de cambio de los tomadores de decisiones.

Hernández, por su parte, también da un lugar preponderante a las instituciones. Expone cómo cambios en el contexto socioecónómico o político pueden propiciar una situación en la que actores institucionales que existían de manera latente cobran relevancia e inciden de manera directa en el sistema político. En este caso fueron los gobernadores y actores locales, que surgen en el escenario político con una renovada fuerza y que se vuelven cruciales en la redefinición del PRI.

En su artículo "El liderazgo político en la presidencia de Felipe Calderón”, José Luis Méndez propone analizar el liderazgo político a partir de tres elementos: "agenda pertinente", "palanqueo inclusivo" y "estilo decisorio equilibrado". Después de estudiar el 
periodo presidencial de Calderón, el autor llega a la conclusión de que el presidente "se planteó objetivos poco factibles (avanzar en la guerra contra el narcotráfico y posteriormente aprobar varias reformas estructurales), los cuales buscó realizar según estrategias inadecuadas (una ofensiva punitiva militar generalizada y una orientación predominantemente unilateral y plebiscitaria, respectivamente), por lo que terminó perdiendo cada vez mayor capital político e incluso empeorando el problema que más buscaba resolver". Así, Calderón ejerció un liderazgo político desequilibrado con "tendencia a la arrogancia, la impulsividad y el protagonismo, que probablemente estuvo en el origen de sus errores".

Rodrigo Velázquez muestra el complejo panorama de las relaciones entre los poderes ejecutivo y legislativo en el gobierno del presidente Calderón. Si bien como sostiene Velázquez "el sexenio será recordado por haber obtenido la presidencia con un margen mínimo de diferencia, por la falta de reconocimiento de la izquierda a Felipe Calderón como presidente legítimo, por la guerra emprendida contra el crimen organizado y por la alta tasa delictiva durante su gestión [...] existieron otras acciones y leyes impulsadas por el presidente de gran trascendencia para la vida política, económica y social del país". Según el autor, "ni el sistema presidencial, el multipartidismo, ni la ausencia de mayoría del partido del presidente en el Congreso produjeron una parálisis legislativa, aunque sí dificultaron la aprobación de algunas reformas estructurales”. Para verificar sus argumentos, Velázquez muestra cómo

cuantitativamente el presidente Calderón tuvo éxito en pasar su agenda legislativa, pues casi $77 \%$ de sus iniciativas fueron aprobadas [...] a pesar de que no contó con una mayoría partidaria que lo respaldara durante su mandato [...] cabe resaltar que Calderón obtuvo un porcentaje de aprobación de su agenda ligeramente mayor al de su predecesor Vicente Fox (74.7\%) [...] No obstante, una valoración cualitativa de la aprobación de la agenda presidencial [...] arroja un resultado mucho más moderado en cuanto a la efectividad del presidente, dado que varias de sus iniciativas clave [...] no se aprobaron. 
Ejemplos de esos fracasos fueron que Calderón no logró el apoyo para crear un impuesto al consumo destinado al combate a la pobreza, permitir a las entidades que implementaran un impuesto local a la gasolina y diesel, ni modificar ordenamientos financieros para fortalecer la banca de desarrollo y promover la inversión. Tampoco se aprobó el mando único policial, la creación de un nuevo código federal de procedimientos penales y el otorgamiento de autonomía a la Procuraduría General de la República. La reforma energética propuesta tuvo el mismo destino de las anteriores. Ahora bien, según Velázquez el hecho de que las reformas estructurales se aprobaron en 2013 bajo el mismo marco institucional y contexto político que en las administraciones anteriores sugiere que no son las variables institucionales, sino otro tipo de factores -tales como el timing, la creación de acuerdos políticos estables y la capacidad de liderazgo- que pueden dar mejor cuenta de la falta de aprobación de los cambios de gran envergadura.

En "La protección social en salud durante el gobierno de Calderón”, Laura Flamand y Carlos Moreno-Jaimes estudian la evolución del Seguro Popular durante el gobierno de Calderón. Para comprender la política social del gobierno de Calderón, los autores resaltan algunas de las continuidades de los gobiernos panistas. Así, en 2003 durante el gobierno de Vicente Fox se promulgó la Ley General de Desarrollo Social (LGDS) y se creó el Consejo Nacional de Evaluación de Política Social. Según los autores, la LGDS se basa en un enfoque de derechos y en una visión multidimensional de la pobreza. La administración de Fox creó el Seguro Popular, que se desarrollaría durante el gobierno de Calderón que planteó como meta la cobertura universal en servicios de salud. Los autores encuentran que "el Seguro Popular surgió de un diagnóstico sólido y de una preocupación fundada sobre la necesidad de hacer efectiva la protección social en salud y un gasto sanitario más equitativo. Sin embargo, sus efectos sobre el gasto de bolsillo y sobre los servicios de salud en general han resultado bastante limitados". Flamand y Moreno-Jaimes atribuyen estos resultados a que el gasto público en salud sigue siendo relativamente bajo y al carácter descentralizado de los serivcios sanitarios que atienden a la población no asegurada. 
En términos teóricos es posible argumentar, por una parte, que hay una dependencia del camino en la política de salud y, por otra, que la realidad institucional mexicana caracterizada por el federalismo tiene como consecuencia servicios de salud de calidades muy diversas. A partir de una comparación con otros países de América Latina, Flamand y Moreno-Jaimes muestran cómo la proporción del PIB destinada al gasto social en México que ascendió a $11.3 \%$ en 2010 es muy baja comparada con la de Argentina $(27.8 \%)$, Brasil $(26.4 \%)$ o Chile (15.2\%). Este rezago se repite en el área específica de salud. Los gobiernos panistas aumentaron los recuros del Seguro Popular que han crecido de manera constante pasando de $0.1 \%$ del gasto total en desarrollo social en 2003 a $3 \%$ en 2010. Sin embargo, los resultados no son muy alentadores, debido a que según los datos "el gasto público en salud de México como proporción del PIB sigue siendo menor al de Argentina y Chile. Más aún, aunque el gasto público ha aumentado considerablemente, el privado (donde se incluye el gasto de bolsillo con sus efectos perniciosos) representa todavía 78.8\%”. Es decir, los hogares mexicanos tienen que utilizar una mayor proporción de sus ingresos en los gastos de salud, que las familias de otros países latinoamericanos con ingresos similares; $y$, dada la muy desigual distribución del ingreso del país, esto alienta un sistema profundamente inequitativo. Si agregamos que más que un solo sistema de salud pública existen 32, con infraestructuras sanitarias diversas, el sistema es aún más desigual. Los autores finalizan su análisis comparando algunas propuestas de universalización del sistema de salud. Flamand y Moreno-Jaimes concluyen que "la propuesta de universalización de Funsalud, igual que la de Seguro Popular en sus orígenes, presta escasa atención a los servicios estatales de salud y a su patente heterogeneidad. Muy probablemente el esquema de descentralización heredado de la década de 1990, sobre el cual se ha montado, por mandato jurídico, el Seguro Popular, continuará siendo la base organizativa de la provisión de los servicios de salud. El texto de Flamand y Moreno-Jaimes nos recuerda la discusión de Juan Linz y Alfred Stepan ${ }^{1}$ sobre los problemas del federalismo,

${ }^{1}$ Juan Linz y Alfred Stepan, "Inequality Inducing and Inequality Reducing 
como una solución política con efectos no buscados graves en términos de equidad. El estudio de federalismos más igualitarios como el canadiense o el alemán, sin duda presenta casos estimables para estudiar.

Los "nuevos" movimientos sociales en México es el tema del artículo de Ilán Bizberg. El autor busca defender "la idea de que a pesar de que es importante analizar la capacidad de los movimientos sociales para impactar el sistema político, es prioritario estudiarlos en función del sentido que ellos mismos otorgan a su acción”. En otras palabras, Bizberg se aleja de la teoría de movilización de recursos y abreva de la escuela accionalista de Alain Touraine. "Desde esta perspectiva, movimientos que parecen poco importantes, si se los mira con base en su impacto político inmediato, pueden estar fuertemente cargados de un sentido ético, el cual puede (o no) tener una mayor influencia en el futuro, o en un lugar distinto al de su surgimiento". El trabajo de Bizberg se centra en el Movimento por la Paz con Justicia y Dingidad y el de los jóvenes \#YoSoy132. El autor califica a estos movimentos como nuevos movimientos sociales por tener seis características: 1) se crearon desde abajo, no desde la esfera política, por lo tanto su orientación es más social y cultural que política; 2) siguiendo a Touraine y Arato, estos movimientos se definen como auto-limitados, refiriéndose a que no pretenden adquirir poder político, ni infuir en él, ni tampoco vincularse con los partidos o con el Estado; 3) rechazan la política tal y como se practica en sus países, pero no lo político; 4) tienden a afirmar un nuevo tipo de ciudadanía que rechaza el clientelismo, demandan derechos más que concesiones; 5) apuntan hacia el sujeto mismo, hacia la capacidad de ser sujeto...; 6) están des-territorializados, en tanto que reivindican conflictos que rebasan cualquier territorio, nación, país y se refieren al mundo actual de la globalización. Sin duda este artículo continúa un debate muy amplio en la discusión sobre movimientos sociales,

Federalism", ponencia presentada en el World Congress of the International Political Science Association, 1-5 de agosto de 2000, Quebec, Canadá. Alfred Stepan, "Toward a New Comparative Politcs of Federalism, Multinaitonaism and Democracy", en Edward L. Gibson, Federalism and Democracy in Latin America, The Johns Hopkins University Press, 2004, pp. 29-84. 
no sólo en México, sino en el mundo, caracterizado por múltiples movimientos que, como afirma Bizberg siguiendo a Amartya Sen, distinguen a un sujeto de un individuo. El "individuo (utilitario) está definido por el deseo de libertad negativa, de perseguir sus intereses sin tener que involucrarse en lo público [...] el sujeto se define con base en la libertad positiva, que tienen un contenido, básicamente el derecho a ejercer efectivamente la libertad con toda autonomía”.

Sin duda, el trabajo de Bizberg abre una discusión fundamental en el tema de los movimientos sociales. Si bien consideramos fundamental el análisis de la cara interna de los movimientos (el fortalecimiento de nuevas y poderosas identidades), nos parece que no se puede dejar de lado la cara externa y sus resultados sobre la política del Estado mexicano. ${ }^{2}$

El último artículo de este número es el trabajo de Jean-François Prud'homme. Éste parte del hecho de la baja satisfacción de los mexicanos con la democracia, para luego analizar el cambio político que ha ocurrido en México durante los últimos veinticinco años, especialmente el ocurrido en las instituciones gubernamentales y partidistas, así como en la sociedad civil y grupos de interés. El autor concluye que la situación de la democracia en México no es catastrófica, aunque destaca que sí hay un desencanto con este sistema político, derivado de los pobres resultados que ha tenido en términos de reducción de desigualdad y pobreza y de la precariedad del Estado de derecho. Al igual que otros de los artículos aquí incluidos, este texto resalta la importancia de las instituciones, especialmente de la necesidad de fortalecer las capacidades estatales para lograr avanzar hacia la consolidación democrática. Pero, más allá de las instituciones formales, señala la relevancia de robustecer los arreglos informales propios de la democracia, una tarea que no sólo toca al Estado, sino también a la sociedad.

${ }^{2}$ Una propuesta que busca analizar ambos procesos es la desarrollada por Sidney Tarrow y Charles Tilly en "Contentious Politics and Social Movements", en The Oxford Handbook of Comparative Politics, Oxford, Oxford University Press, 2007 pp. $435-461$. 
No podemos cerrar esta introducción sin mencionar el regreso del PRI a la presidencia de la República y los primeros meses de gobierno del presidente Peña Nieto. El 1 de julio de 2012, Enrique Peña Nieto, candidato de la coalición Compromiso por México, formada por el PRI y el Partido Verde Ecologista de México, ganó la elección presidencial con $38.2 \%$ de los votos. Han sido varias las explicaciones que se han dado al retorno del PRI a la presidencia. Hay quien ha señalado el aprendizaje que obtuvo al tener que competir electoralmente, la cohesión que logró en torno a un candidato de unidad, la renovación de sus cuadros, pero todos coinciden en que el factor más importante que influyó en su regreso al gobierno federal fue la gran insatisfacción del electorado después de doce años de panismo.

La gran pregunta que se antojaba con la toma de posesión del nuevo gobierno es si regresaría el autoritarismo. El 2 de diciembre de 2012, el gobierno anunció el Pacto por México, firmado por PRI, PAN y PRD. Que el presidente y la oposición consensuaran una agenda legislativa que incluyera las reformas estructurales fue un hecho inusual en la política mexicana. Dado el contexto de gobierno sin mayoría, al presidente Peña Nieto le hubiera sido muy difícil aprobar solo estas reformas. A los pocos meses de su existencia el Pacto logró producir reformas constitucionales importantes en materia fiscal, energética educativa y telecomunicaciones, entre otras. Sin embargo, al momento de discutir las leyes secundarias, la colaboración legislativa perdió el impulso y se fue agotando. En enero de 2014, el Pacto se fue desvaneciendo al punto de desaparecer.

El escenario con el que inicia 2015, año en el que 17 estados tendrán elecciones y en que se renovará la Cámara de Diputados, es complicado. Los partidos pasan por una crisis de representatividad y legitimidad muy severa. El PAN se muestra incapaz de presentar una agenda clara y novedosa. En el PRD siguen las pugnas internas y se acrecienta la falta de credibilidad en sus líderes a partir del caso de Iguala. El PRI sufre un tremendo desgaste derivado de la incapacidad gubernamental de hacer frente a la crisis de seguridad, violencia e impunidad. Es entonces plausible pensar que los protagonistas de la elección de 2015 serán los movimientos 
sociales, la sociedad civil y los candidatos independientes. Habrá que ver cuáles serán los resultados y si los perdedores serán los de siempre.

Hoy la desaparición forzada de 43 estudiantes de la Escuela Normal de Ayotzinapa ha provocado un movimiento social que vuelve a reclamar la incapacidad del Estado mexicano. Ya desde 2013 Javier Sicilia había demandado que la ley de Seguridad Humana y Ciudadana debía poner: "énfasis en los derechos humanos, en un cambio de estrategia en el combate al crimen, en una limpieza real de los delincuentes que hay en todos los órdenes de gobierno, y en la necesaria construcción de un México donde quepan muchos Méxicos" (citado por Bizberg en este número). La ley fue promulgada por el presidente Peña Nieto, pero ésta no cambió la estrategia de combate al crimen, no limpió de delincuentes los órdenes de gobierno y no ha puesto en el centro de su política la atención a las víctimas de la violencia. Es muy probable que esta situación sea parte de la explicación de la creciente fuerza de las nuevas movilizaciones. 